\title{
Study of Amorphous-Crystalline Phase Transformations by DSC and Dilatometer in the Case of Al-Based Amorphous Alloys
}

\author{
Éva Fazakas, ${ }^{1}$ Béla Varga, ${ }^{2}$ and Lajos Károly Varga ${ }^{1}$ \\ ${ }^{1}$ Wigner Research Centre for Physics, Institute for Solid State Physics and Optics, Hungarian Academy of Sciences, P.O. Box 49, \\ Budapest 1525, Hungary \\ ${ }^{2}$ Faculty of Materials Science and Engineering, Transylvania University, Bulevardul Eroilor, No. 29, 500036 Brasov, Romania
}

Correspondence should be addressed to Éva Fazakas, efazakas@szfki.hu

Received 21 August 2012; Accepted 11 September 2012

Academic Editors: R. Hebert and A. Tuissi

Copyright ( 2012 Éva Fazakas et al. This is an open access article distributed under the Creative Commons Attribution License, which permits unrestricted use, distribution, and reproduction in any medium, provided the original work is properly cited.

\begin{abstract}
The amorphous-crystalline transformation is studied by DSC and dilatometer. From the DSC signal the characteristic temperatures and the heat evolved during each transformation step can be determined. The dilatometer depicts the thermal contractions accompanying the changes in topological short range order. Although the characteristics temperatures determined by DSC and dilatometer, two methods are slightly different their dependences on the heating rate are very similar, where from the activation energies of each transformation steps can be determined using the Kissinger plots. As an example, two aluminum-based amorphous ribbon samples $\left(\mathrm{Al}_{88} \mathrm{Mm}_{5} \mathrm{Ni}_{5} \mathrm{Co}_{2}\right.$ and $\left.\mathrm{Al}_{85} \mathrm{Y}_{8} \mathrm{Ni}_{5} \mathrm{Co}_{2}\right)$ will be measured and compared.
\end{abstract}

\section{Introduction}

20 years have been passed since the discovery of the first ductile Al-based amorphous alloy ribbons with superior mechanical properties compared to the conventional aluminum alloys $[1,2]$. These ribbons have been obtained by melt spinning technique starting from a multicomponent ingot contained as a rule rare earth (RE) metal and one or two late transition metals (TMs) [3]. It has been found that alloys with high glass forming ability (low critical cooling rate for glass formation or large critical thickness) are the socalled strong metallic glasses in the Angell plot [4]. Unfortunately, the Al-based glasses belong to the fragile glasses with low glass forming ability and consequently no bulk metallic glass (BMG) exits on Al-base. The bulk amorphous samples can be obtained only by hot consolidation of the amorphous ribbon flakes, which should be performed below the transformation temperature. Therefore, the thermal stability of these ribbons (in amorphous or nanocrystalline state) marks a limit of their applicability, and the study of the kinetics of crystallization of Al-based alloys is an important task to which several studies have been devoted so far (for a review, see [5]).

In order to reduce the price of the alloy in this paper we have studied a composition containing Mischmetal instead of pure RE element. Mischmetal (Mm) is a natural mixture of rare earth metals; typical composition contains $48 \%$ cerium, $25 \%$ lanthanum, $17 \%$ neodymium, and $5 \%$ praseodymium, with the balance being the other lanthanides. Many studies were devoted to compare the behavior of $\mathrm{Mm}$-substituted alloys with those with pure rare earth elements [5-7]. In the present paper the kinetics of crystallization are studied for two alloys of nominal compositions $\mathrm{Al}_{85} \mathrm{Y}_{8} \mathrm{Ni}_{5} \mathrm{Co}_{2}$ and $\mathrm{Al}_{88} \mathrm{Mm}_{5} \mathrm{Ni}_{5} \mathrm{Co}_{2}$ by DSC and dilatometer. We have chosen these two compositions because they show big differences during dilatometer investigations although both show three transformation steps in their DSC patterns. The dilatometer is sensitive to the volume changes accompanying the amorphous-crystalline transformation, that is, to the change in topological short range order (TSRO). In contrast with dilatometer, the DSC is sensitive to the heat evolved during the formation of new phases, that is, to the changes in 
chemical short range order (CSRO). In addition, Vickers microhardness data are presented to compare their mechanical properties.

\section{Experimental}

The $\mathrm{Al}_{88} \mathrm{Mm}_{5} \mathrm{Ni}_{5} \mathrm{Co}_{2}(\mathrm{Mm} 5)$ and $\mathrm{Al}_{85} \mathrm{Y}_{8} \mathrm{Ni}_{5} \mathrm{Co}_{2}$ (Y8) alloy ingots were prepared by induction melting under argon atmosphere [8]. High-purity (>99.9 at\% purity) elements were placed in a water-cooled copper boat and held above the melting point to homogenize the ingot. The as-prepared ingot was used to prepare ribbon samples (thickness was about $20-22 \mu \mathrm{m}$ and the width $2.5-3 \mathrm{~mm}$ of the ribbon) by a single-roller melt-spinning technique under protective atmosphere at a wheel speed of $25^{\circ} \mathrm{m} / \mathrm{s}$. Bulk amorphous Mm5 and Y8 samples can be produced by hot consolidation of the flakes produced by cryogenic chopping of melt-spun amorphous ribbons. The evolution of the microstructure of the as-quenched samples was examined by X-ray diffraction (Bruker D8). Differential scanning calorimeter (PerkinElmer TGA7) and dilatometer measurements (Linseis L75H) under argon atmosphere were used to study the structural transformations up to the melting point.

\section{Results and Discussion}

Figures 1 and 2 show the XRD patterns obtained from samples annealed up to the end of crystallization sequences. Amorphous patterns obtained for the as-cast ribbons are also shown. The peaks were identified to correspond to fcc $\alpha$-Al as the main component; hexagonal $\mathrm{Al}_{3} \mathrm{Y}$ and orthorhombic $\mathrm{Al}_{3} \mathrm{Ni}$ for $\mathrm{Al}_{85} \mathrm{Y}_{8} \mathrm{Ni}_{5} \mathrm{Co}_{2}$ and orthorhombic $\mathrm{Al}_{11} \mathrm{Mm}_{3}$ and orthorhombic $\mathrm{Al}_{3} \mathrm{Ni}$ for $\mathrm{Al}_{88} \mathrm{Mm}_{5} \mathrm{Ni}_{5} \mathrm{Co}_{2}$, respectively. Measuring the XRD pattern after different crystallization stages one can remark a narrowing of the fcc $\alpha$-Al peak indicating that grain growth of this phase takes place during the three crystallization stages.

The two glasses show very different crystallization sequences. For Y8 an endothermic prepeak (see Figure 3) just before the main crystallization stage can be observed as an evidence for the glass transition. Whereas for the Mm5 sample a small exothermic prepeak (see Figure 4), more than $100 \mathrm{~K}$ degree separated from the main crystallization stage, denotes the primary crystallization of the fcc $\alpha$ $\mathrm{Al}$ in a residual amorphous matrix. The crystallization transformation followed on the dilatometer scans (Figures 5 and 6) shows significant differences compared to the DSC scans: for the Y8 samples (Figure 5) there is apparently only one crystallization step on the derivative of the length change, $\Delta L$, contradicting the DSC scan (Figure 3), whereas for the M5 sample all the 3 crystallization stages are well marked (Figure 6) in accordance to the DSC scans (Figure 4). However, enlargement of the details around the transformation peak (see the inset in Figure 5) reveals the existence of the three transformation steps at relative low heating rates for the Y8 sample as well. For $10 \mathrm{~K} / \mathrm{min}$ heating rate one can observe a change in the volume of the sample even before the onset of the glass transition marked by the

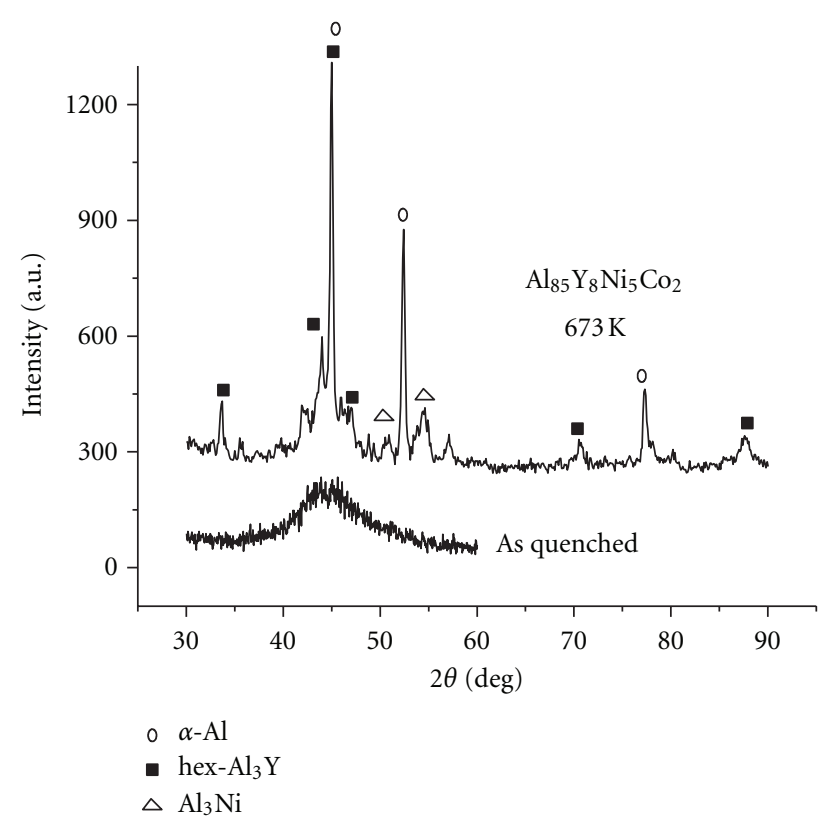

FIGURE 1: XRD patterns for the samples of the as-quenched $Y$ alloy being heated up to $673 \mathrm{~K}$ temperatures at $10 \mathrm{~K} / \mathrm{min}$.

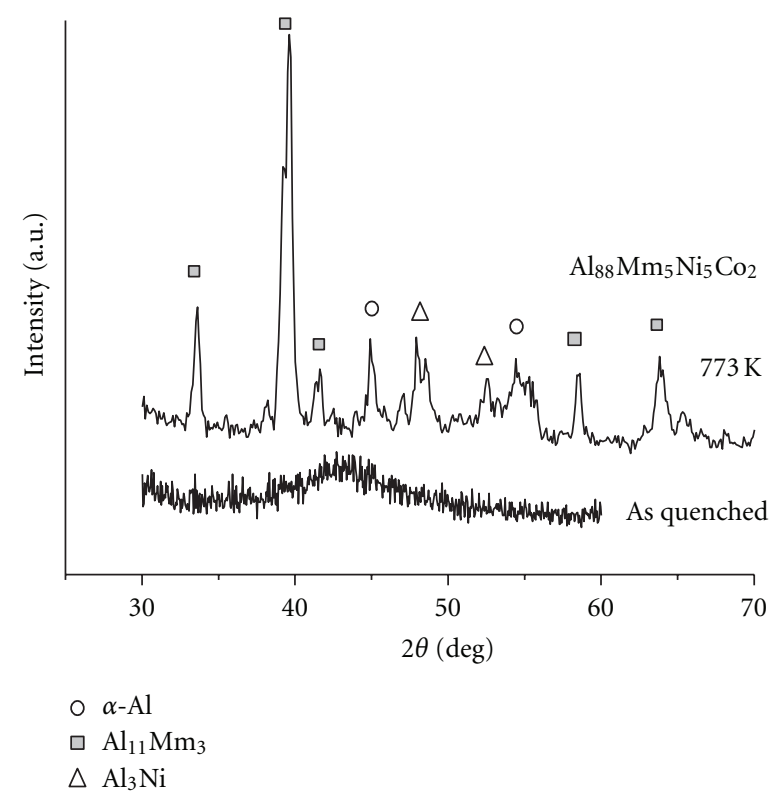

FIGURE 2: XRD patterns for the samples of the as-quenched Mm alloy being heated up to $773 \mathrm{~K}$ temperatures at $10 \mathrm{~K} / \mathrm{min}$.

endothermic peak in DSC pattern. More investigations are necessary to separate the free volume elimination caused contraction during the relaxation of the amorphous state and the contraction caused by the glass transition into the supercooled liquid state. At the moment we concentrate on the devitrification process, which depends mostly on the RE content. For high $\mathrm{Al}$ content (88 at \% $\mathrm{Al}$ in $\mathrm{Mm} 5$ sample) we observe the precrystallization peak of the nanosized $\alpha$-Al, characteristic for the hypoeutectic compositions at the edge 


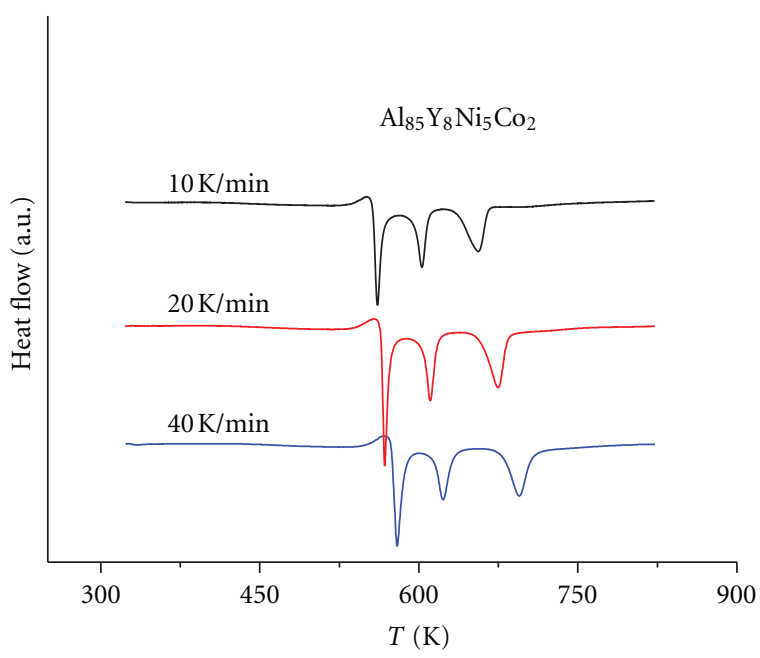

FIgURE 3: DSC scans at different heating rate for as-cast samples of the $\mathrm{Al}_{85} \mathrm{Y}_{8} \mathrm{Ni}_{5} \mathrm{Co}_{2}$ alloys.

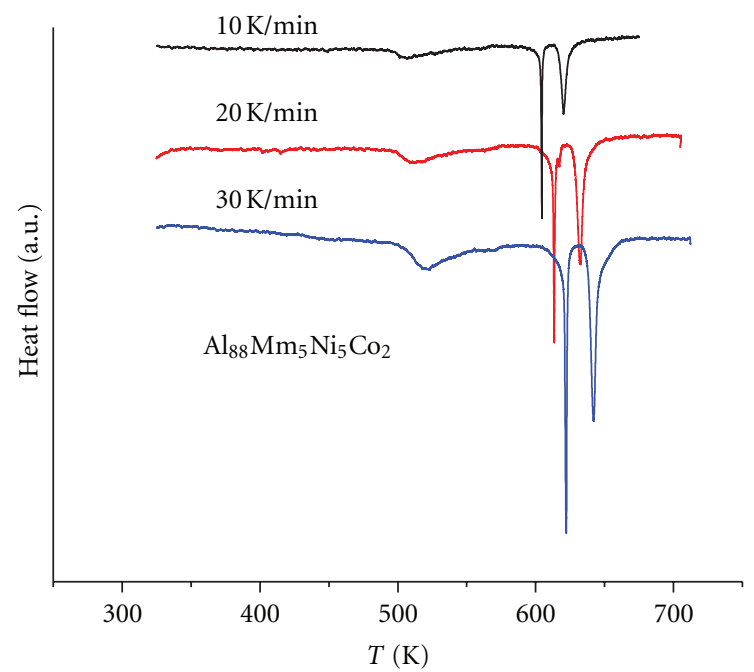

FIGURE 4: DSC scans at different heating rate for as-cast samples of the $\mathrm{Al}_{88} \mathrm{Mm}_{5} \mathrm{Ni}_{5} \mathrm{Co}_{2}$ alloys.

of glass forming ability. The devitrification proceeds on by successive decomposition of the residual amorphous phase into compound phases at higher temperatures. For lower $\mathrm{Al}$ content (85 at \% Al in $\mathrm{Y} 8$ sample) the amorphous state is more stable showing even glass transition into supercooled liquid state which stability is usually measured by the difference between the first crystallization peak and the Tg (about $30 \mathrm{~K}$ for Y8 sample). This supercooled liquid nucleates as a whole at the onset of crystallization into $\alpha$-Al and metastable compound phases [9], that is, the majority of the changes in the topological short range order take place. As a result a huge contraction peak appears for the Y8 sample and the subsequent small contractions belong to the small volume changes accompanying the changes in CSRO during the diffusion rearrangement of the metastable crystalline phases into stable stoichiometric compound phases. The change of the chemical short range order with increasing

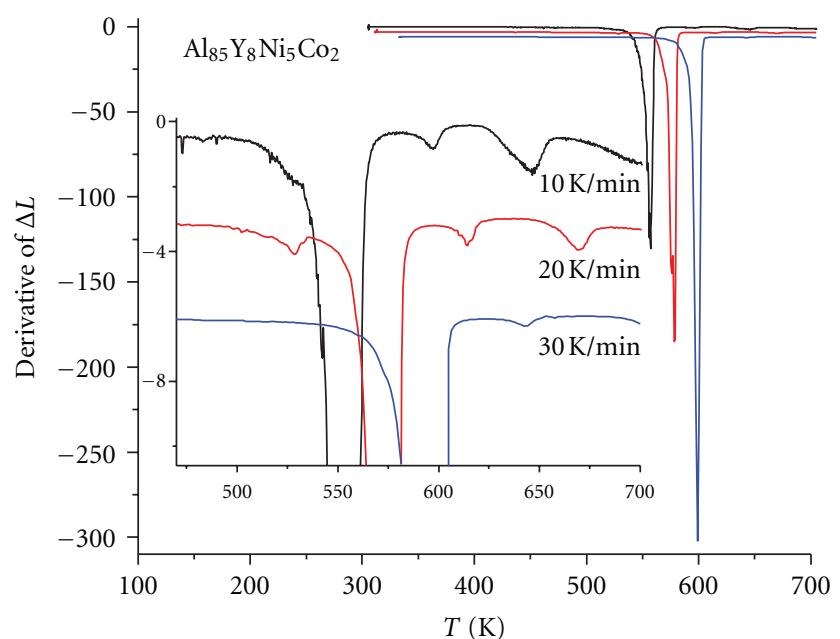

Figure 5: Dilatometer scans at different heating rate for as-cast $\mathrm{Al}_{85} \mathrm{Y}_{8} \mathrm{Ni}_{5} \mathrm{Co}_{2}$ ribbons. The inset shows a magnified detail around the main crystallization peak.

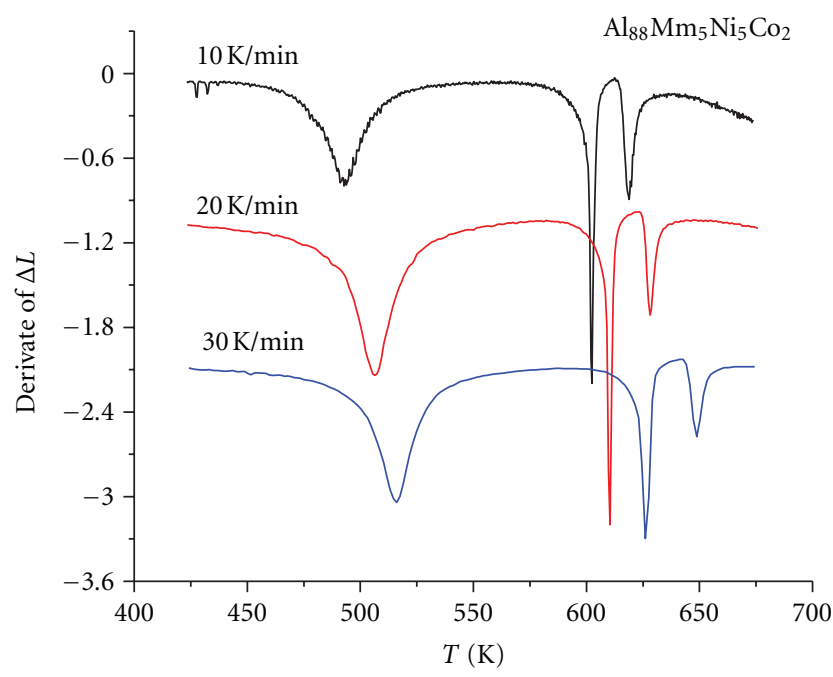

Figure 6: Dilatometer scans at different heating rate for as-cast samples of the $\mathrm{Al}_{88} \mathrm{Mm}_{5} \mathrm{Ni}_{5} \mathrm{Co}_{2}$ alloys.

temperature produces similar heat effect for the Y8 sample as the decomposition of the residual amorphous phase for the Mm5 sample. The coincidence of the number of the main crystallization peaks is just fortuitous, the devitrification process is completely different for the two compositions. For the Mm5 sample the transformation steps are dominated by the subsequent decomposition of the residual amorphous matrix, whereas for the Y8 sample the transformation steps are determined by the evolution of the metastable compound phase nucleated in the first step. The three crystallization steps are as follows. For the Mm5 sample: $\mathrm{Am} \rightarrow \mathrm{Am}^{\prime}+$ supersaturated nano- $\alpha-\mathrm{Al} \rightarrow \mathrm{Al}^{\prime \prime}+\alpha-\mathrm{Al}+\mathrm{Al}_{3} \mathrm{Ni}+\mathrm{Al}_{3} \mathrm{Co} \rightarrow$ $\alpha-\mathrm{Al}+\mathrm{Al}_{3} \mathrm{Ni}+\mathrm{Al}_{3} \mathrm{Co}+\mathrm{Al}_{11} \mathrm{Mm}_{3}$. For the Y8 sample: $\mathrm{Am} \rightarrow$ supersaturated nano- $\alpha$ - $\mathrm{Al}+$ metastable Xcryst $\rightarrow \alpha$ $\mathrm{Al}+\mathrm{X}^{\prime}+\mathrm{Al}_{3} \mathrm{Ni}+\mathrm{Al}_{3} \mathrm{Co} \rightarrow \alpha-\mathrm{Al}+\mathrm{Al}_{3} \mathrm{Ni}+\mathrm{Al}_{3} \mathrm{Co}+\mathrm{Al}_{3} \mathrm{Y}$. The three contraction peaks on the dilatometer scan of 


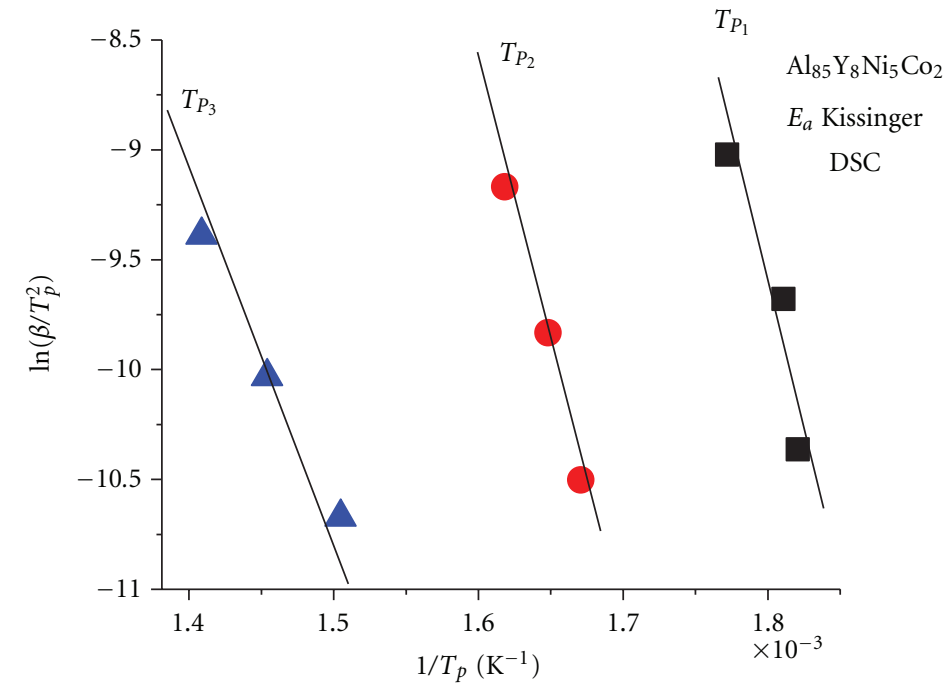

FIGURE 7: Kissinger plots for the glass transition and crystallization peaks for the Y8 alloy.

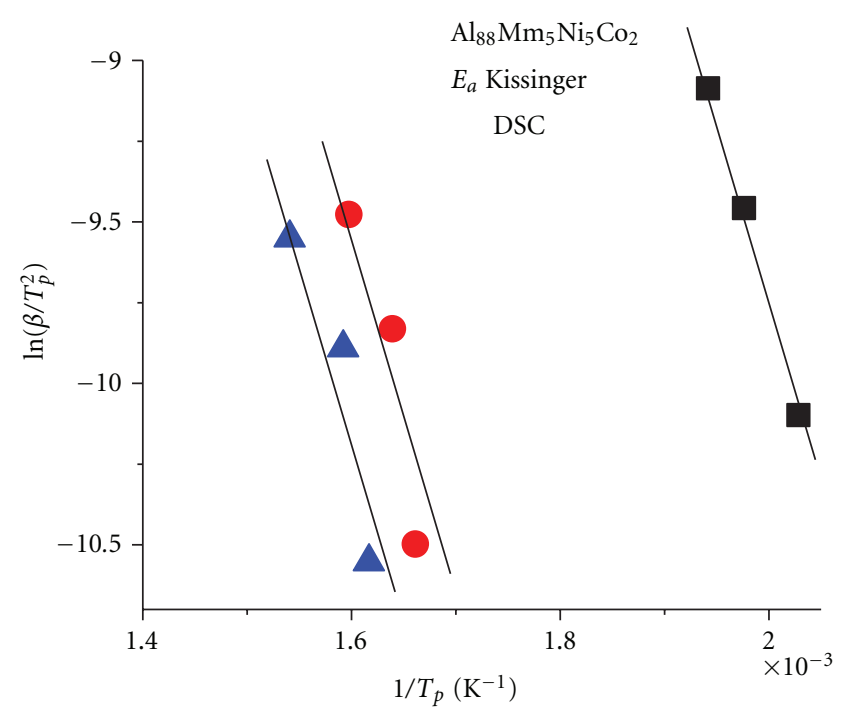

FIGURE 8: Kissinger plots for the crystallization peaks for the Mm5 alloy.

the Mm5 sample (Figure 6) mark the TSRO changes in the initial amorphous (Am) and subsequent residual amorphous $\left(\mathrm{Am}^{\prime}\right.$ and $\left.\mathrm{Am}^{\prime \prime}\right)$ phases. The accompanying CSRO changes produce the three DSC exothermic peaks (Figure 4). The apparently single dilatometer peak for the Y8 marks the decomposition of the majority of the initial amorphous phase in the first crystallization step, and the subsequent diffusion rearrangement of the metastable crystalline phase produces hardly observable volume changes. These decompositions of the metastable phase give rise to the second and third exothermic peaks in the DSC scan of the Y8 sample (Figure 3). The parameters of the amorphous-crystalline transformation are collected in the Tables 1 and 2 for the Mm5 and Y8 samples, respectively.
TABle 1: Crystallization parameters for $\mathrm{Al}_{85} \mathrm{Y}_{8} \mathrm{Ni}_{5} \mathrm{Co}_{2}$ alloy obtained by DSC and dilatometer.

\begin{tabular}{lccccccc}
\hline \multicolumn{1}{c}{$\mathrm{Al}_{85} \mathrm{Y}_{8} \mathrm{Ni}_{5} \mathrm{Co}_{2}$} \\
\multirow{3}{*}{ Dilatometer } \\
$\beta(\mathrm{K} / \mathrm{min})$ & $\begin{array}{c}T_{p 1} \\
(\mathrm{~K})\end{array}$ & $T_{p 2}$ & $T_{p 3}$ & $T_{g}$ & $T_{p 1}$ & $T_{p 2}$ & $T_{p 3}$ \\
& 551 & 591 & 640 & 532 & 560 & 603 & 654 \\
\hline 10 & 568 & 607 & 662 & 534 & 568 & 611 & 674 \\
20 & 574.5 & - & - & - & - & - & - \\
30 & & & & 545 & 579 & 623 & 695 \\
40 & 2.3 & & & 2.25 & 2.64 & 2.7 & 1.43 \\
\hline$E_{a}(\mathrm{eV})$ & & & & & & & \\
\hline
\end{tabular}

TABLE 2: Crystallization parameters for $\mathrm{Al}_{88} \mathrm{Mm}_{5} \mathrm{Ni}_{5} \mathrm{Co}_{2}$ alloys obtained by DSC and dilatometer.

\begin{tabular}{lcccccc}
\hline \multicolumn{9}{c}{$\mathrm{Al}_{88} \mathrm{Mm}_{5} \mathrm{Ni}_{5} \mathrm{Co}_{2}$} \\
$\beta(\mathrm{K} / \mathrm{min})$ & $\begin{array}{c}T_{p 1} \\
(\mathrm{~K})\end{array}$ & $T_{p 2}$ & $T_{p 3}$ & $T_{p 1}$ & $T_{p 2}$ & $T_{p 3}$ \\
& $(\mathrm{~K})$ & $(\mathrm{K})$ & $(\mathrm{K})$ & $(\mathrm{K})$ & $(\mathrm{K})$ \\
\hline 10 & 493 & 602 & 618.5 & 506 & 604 & 621 \\
20 & 506 & 610 & 628 & 512 & 612 & 631 \\
30 & 515 & 626 & 649 & 520 & 622 & 641 \\
\hline$E_{a}(\mathrm{eV})$ & 1.43 & 2.01 & 1.51 & 1.38 & 2.03 & 1.79 \\
\hline
\end{tabular}

The activation energies $\left(E_{a}\right)$ of the 3 crystallization steps have been determined from the Kissinger plots based on the shift of the peaks as a function of the heating rate, $\beta$ :

$$
\begin{aligned}
\ln \left(\frac{\beta}{T_{p}^{2}}\right) & =-\frac{E_{a}}{R T_{p}}+C, \ln \left(\frac{\beta}{T_{p}^{2}}\right) \\
& =-\frac{E_{a}}{R T_{p}}+C
\end{aligned}
$$

where $R$ is the universal gas constant. 
These activation energies are collected also in the Tables 1 and 2.

In the Figures 7 and 8 the collected Kissinger plots for all the peaks are shown for the samples $\mathrm{Y} 8$ and $\mathrm{Mm} 5$, respectively. From the scatter of the data the error of the activation energy is estimated to be $\pm 0.2 \mathrm{eV}$.

Perusal of the Tables 1 and 2 shows that the DSC and the dilatometer methods give similar values for the activation energies within the error of the $E_{a}$ determinations. The values of the crystallization peaks are in general lower for the dilatometer method compared to the DSC data. The dilatometer data for the peak temperatures of the second and third crystallization steps deviates more and more with increasing heating rate from the reference DSC data, but these deviations remain below 10 degree for the Mm5 sample. The glass transition appeared only for the Y8 sample (see Table 1), which shows no primary crystallization. The determination of the glass transition temperature, $T_{g}$, is somehow ambiguous. In this work, we have adopted the intersection of the steepest slope with the baseline, which might be the glass transition onset [10]. However, other authors [9] define $T_{g}$ as the inflexion point of the curve denoting the endothermic effect. The latter definition gives higher $T_{g}$ values, and, consequently, the super cooled liquid region (defined as $\Delta T=T_{x}-T_{g}$ ) decreases (in our case by about $10 \mathrm{~K}$ ). The $T_{g}$ is also shifting to higher values as a function of heating rate and from these shifted $T_{g}$ data an activation energy can be determined for the glass transition as well, similar to the crystallization data. The corresponding Kissinger plot for the Y8 sample is presented in Figure 7, and the activation energy determined from the slope of the fitted line is a little bit smaller than the activation energy for the first step of the crystallization.

The thermal stability of the amorphous state measured by the first crystallization temperature is higher for the Y8 sample than for the Mm5 sample. As a consequence, the hot pressure consolidation can be performed at higher temperatures for the Y8 sample.

Vickers microhardness data were determined obtaining $\mathrm{HV}_{0.01}=337 \mathrm{~kg} / \mathrm{mm}^{2}$ for the Mm5 and $309 \mathrm{~kg} / \mathrm{mm}^{2}$ for $\mathrm{Y} 8$ as cast ribbon samples. Using the $\mathrm{HV}=3 \sigma$ relationship, from these hardness data very similar tensile strength values can be estimated in the as cast state: $\sigma=1120$ and $1030 \mathrm{MPa}$ for the samples Mm5 and Y8, respectively.

\section{Conclusions}

Both the DSC and dilatometer methods are suitable to study the crystallization processes of the amorphous ribbons and for the determination of the activation energy. Based on the different sensitivity of these two methods to the changes in the TSRO and CSRO, we have established that the crystallization steps are evaluated through the decomposition of the residual amorphous phase and of the metastable crystalline compound phase for the Mm5 and Y8 samples, respectively.

The higher thermal stability and the observed wide glass transition region $(\Delta T \sim 30 \mathrm{~K})$ for the $\mathrm{Y} 8$ composition facilitate the future hot pressure consolidation experiments in order to prepare bulk amorphous sample.

\section{Acknowledgments}

This work was supported by Hungarian Grant OTKA 73451 and by Romanian Academy of Sciences.

\section{References}

[1] Y. He, S. J. Poon, and G. J. Shiflet, "Synthesis and properties of metallic glasses that contain aluminum," Science, vol. 241, no. 4873, pp. 1640-1642, 1988.

[2] A. Inoue, K. Ohtera, A. P. Tsai, and T. Masumoto, "New Amorphous Mg-Ce-Ni Alloys with High Strength and Good Ductility," Japanese Journal of Applied Physics," JapaneseJournal of Applied Physics, vol. 27, p. L289, 1988.

[3] C. A. Angell, "Formation of glasses from liquids and biopolymers," Science, vol. 267, no. 5206, pp. 1924-1935, 1995.

[4] A. Inoue, "Amorphous, nanoquasicrystalline and nanocrystalline alloys in Al-based systems," Progress in Materials Science, vol. 43, no. 5, pp. 365-520, 1998.

[5] D. V. Louzguine, A. R. Yavari, and A. Inoue, "Mischmetal as an alloying addition to amorphous materials and glass formers," Journal of Non-Crystalline Solids, vol. 316, no. 2-3, pp. 255260, 2003.

[6] I. T. H. Chang and R. R. Botten, "Heat treatment of rapidly solidified Al-Ni-Mm alloys," Materials Science and Engineering A, vol. 226-228, pp. 183-186, 1997.

[7] H. E. Kissinger, "Reaction kinetics in differential thermal analysis," Analytical Chemistry, vol. 29, no. 11, pp. 1702-1706, 1957.

[8] "Vacuum and Technologies for Metallurgy," http://web.aldvt.de/cms/fileadmin/pdf/prospekte/ALD_Bibel_full.pdf.

[9] D. V. Louzguine and A. Inoue, "Influence of a supercooled liquid on crystallization behaviour of Al-Y-Ni-Co metallic glass," Materials Letters, vol. 54, no. 1, pp. 75-80, 2002.

[10] J. S. Blázquez, E. Fazakas, H. Dimitrov, J. Latuch, L. K. Varga, and T. Kulik, "Effect of substitution of rare earth by mischmetal on the devitrification process of Al-X-Ni-Co (X = Y, Ce, Mm) alloys," Journal of Non-Crystalline Solids, vol. 351, no. 2, pp. 158-166, 2005. 

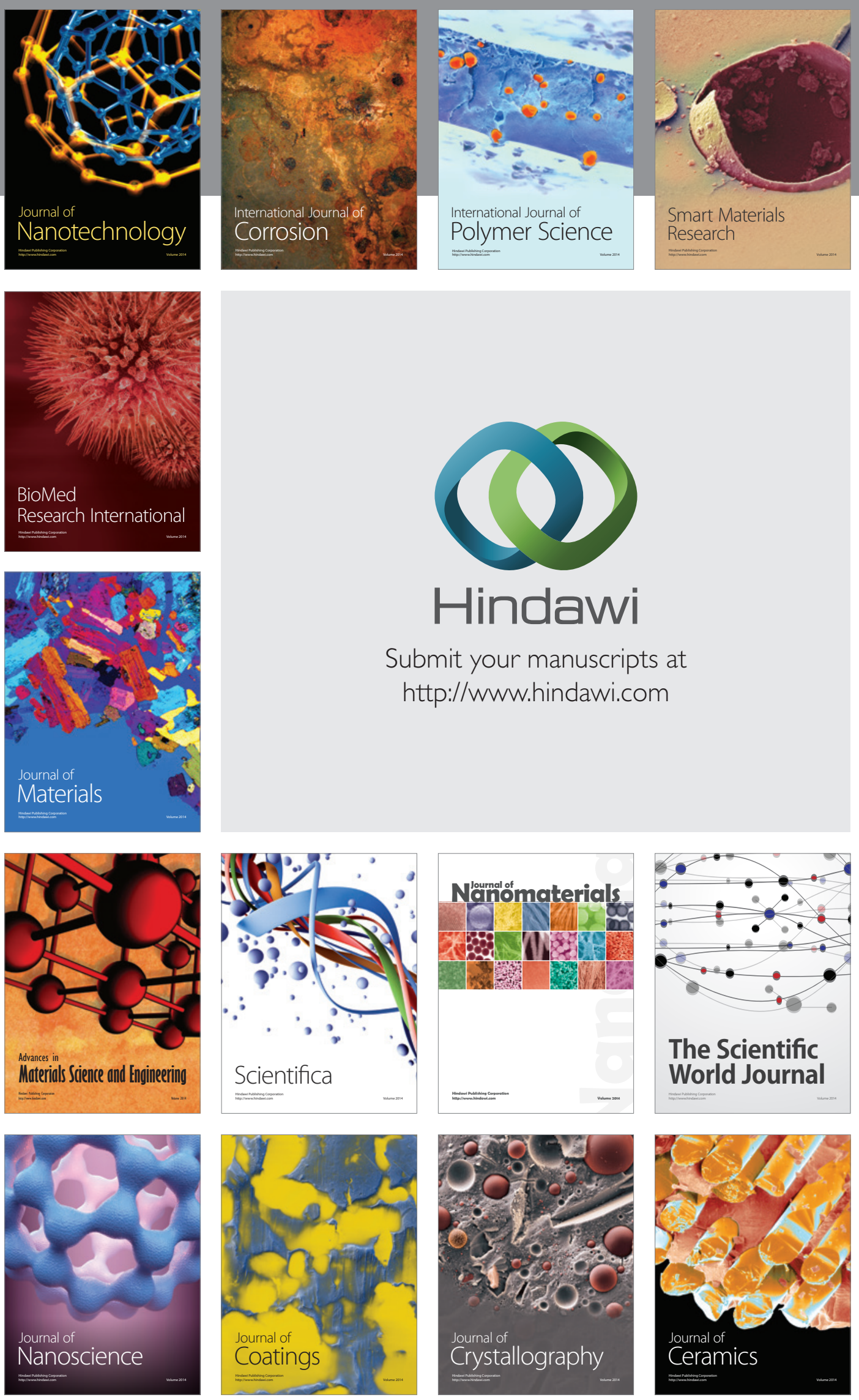

The Scientific World Journal

Submit your manuscripts at

http://www.hindawi.com

\section{World Journal}

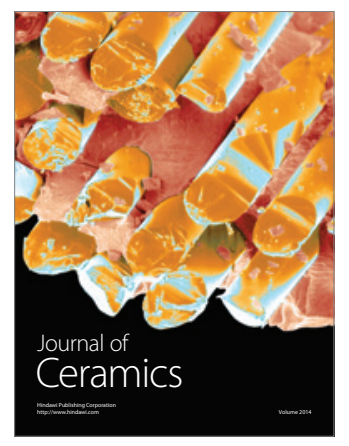

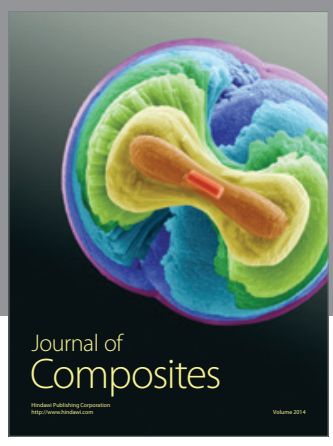
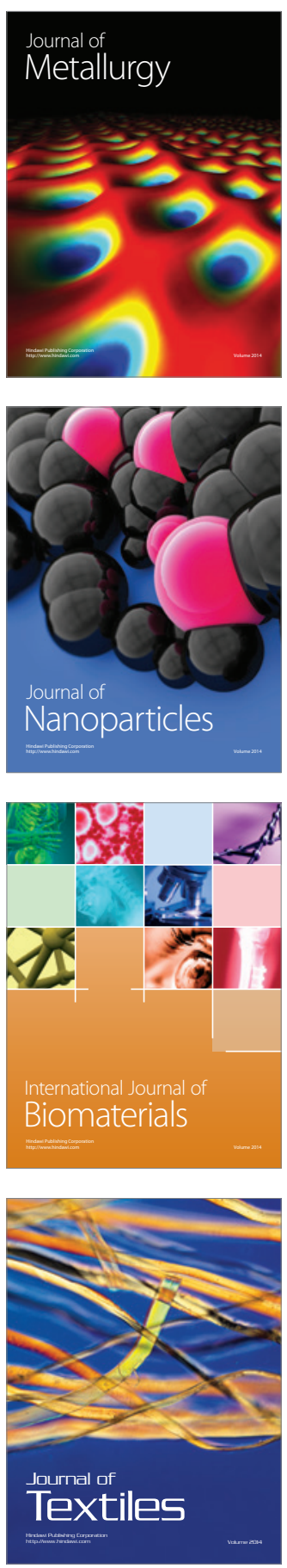